\title{
CASE REPORT \\ Effect of treatment with alendronate in osteogenesis imperfecta type I: a case report
}

\author{
Jun Iwamoto, Tsuyoshi Takeda and Yoshihiro Sato ${ }^{1}$ \\ Department of Sports Medicine, School of Medicine, Keio University, Tokyo, ${ }^{1}$ Department of Neurology, Mitate \\ Hospital, Fukuoka, Japan
}

(Received for publication on December 15, 2003)

\begin{abstract}
A case of osteogenesis imperfecta (OI), which was successfully treated with alendronate is reported. A 41-year-old premenopausal woman with OI type I, who had frequently been experiencing fragile fractures, consulted our clinic because of back pain associated with spinal osteoporosis. She had experienced heart surgery (aortic valve replacement) due to aortic regurgitation 5 years before her first consultation with our clinic. After the surgery, she had been taking warfarin $3 \mathrm{mg} / \mathrm{day}$, and this treatment was continued during our follow-up period. She was treated with alendronate $(5 \mathrm{mg} / \mathrm{day}$, daily) for 18 months. The bone mineral density of the lumbar spine (L2-L4) measured by dual energy X-ray absorptiometry (Norland XR-36) increased for 18 months, and back pain markedly decreased. The urinary cross-linked $\mathbf{N}$-terminal telopeptides of type I collagen and serum bone-specific alkaline phosphatase, osteocalcin, and undercarboxylated osteocalcin levels also markedly decreased. No new fragile vertebral or non-vertebral fractures were observed during the 18 months of treatment. This report provides evidence indicating that treatment with oral alendronate may have the potential to decrease bone turnover, improve the lumbar BMD, reduce back pain, and prevent new fragile fractures in premenopausal women with OI type I. (Keio J Med 53 (4): 251-255, December 2004)
\end{abstract}

Key words: osteogenesis imperfecta, alendronate, bone mineral density (BMD), fracture, bone turnover

\section{Introduction}

Osteogenesis imperfecta (OI) is a heterogeneous group of genetic disorders that affect connective tissue integrity. The hallmark of OI is bone fragility, although other manifestations, which include osteoporosis, dentigenesis imperfecta, blue sclera, easy bruising, joint laxity, and scoliosis, are also common among OI patients. The severity of OI ranges from prenatal death to mild osteopenia without limb deformity. Most forms of OI result from mutations in the genes that encode either the pro $\alpha 1$ or pro $\alpha 2$ polypeptide chains that comprise type I collagen molecules, the major structural protein of bone. ${ }^{1}$

Although OI is a heritable disorder of bone formation, resulting in bone fragility, the activity of cancellous bone remodeling, bone resorption, and/or bone turnover are also increased, ${ }^{2-6}$ and the efficacy of treatment with cyclical intravenous pamidronate for bone fragility in children with OI is established. ${ }^{7-12}$

The fracture rate decreases with maturation in patients with OI. ${ }^{2,13}$ This clinical stability of the disease may be associated with the maturation of bone. Despite the reduced fracture rate, bone mineral density (BMD) usually remains low in adults with OI; however, very few studies have been reported concerning treatment of osteopenia in adults with OI.

A nitrogen-containing bisphosphonate like alendronate is generally accepted as a safe, effective, and well-tolerated treatment for postmenopausal osteoporosis $;^{14-17}$ it increases the lumbar and femoral neck BMD and prevents new vertebral and femoral neck fractures. Alendronate preferentially binds hydroxyapatite and inhibits osteoclast-mediated bone resorption by suppressing the recruitment and activity of osteoclasts and shortening their life span. ${ }^{18}$ Because alendronate is effective for high turnover osteoporosis including postmenopausal osteoporosis, it may be use-

Reprint requests to: Dr. Jun Iwamoto, Department of Sports Medicine, School of Medicine, Keio University, 35 Shinanomachi, Shinjuku-ku, Tokyo 160-8582, Japan, e-mail: jiwamoto@sc.itc.keio.ac.jp 
ful for adults with OI who show increased bone resorption or high bone turnover. An adult case of OI type I with high bone turnover and high fracture rate, which was successfully treated with alendronate, is reported.

\section{Case Report}

A premenopausal woman, 41 years of age, consulted our clinic because of back pain. Despite the subjective symptom of chronic back pain continuing for a couple of years, she had never received treatment for it. Her height was $132 \mathrm{~cm}$, body weight was $31 \mathrm{~kg}$, and body mass index was $17.7 \mathrm{~kg} / \mathrm{m}^{2}$. She had experienced heart surgery (aortic valve replacement) due to aortic regurgitation 5 years before her first consultation with our clinic. After the surgery, she had been taking warfarin 3 $\mathrm{mg} /$ day until her first consultation, and this treatment was continued during our follow-up period. The patient had no past history of metabolic bone diseases other than OI, and had never taken medicine that affected bone metabolism other than warfarin. Three clinical criteria of OI - history of fractures, blue sclera, positive family history - were present. Deformities in the legs such as antero-lateral bowing of the femurs and anterior bowing of the tibiae and deformity in the thoracic and lumbar spine were observed. The patient belonged to Sillence Type I OI. ${ }^{19}$ Back pain level was 7, evaluated quantitatively by assessing the mood of the patient according to face scale score (scores are arranged in decreasing order of mood and numbered from 1-10, with 1 representing the most positive mood and 10 representing the most negative mood). The radiographs of the thoracic and lumbar spine showed scoliotic deformity. Because of this scoliotic deformity, vertebral fractures could not be diagnosed precisely according to the Japanese criteria of vertebral fracture. ${ }^{20,21}$ The patient had experienced more than 20 fractures in the femurs, toes, ribs, and scapulae. Of these fractures, 13 were observed in the femurs. Most of the fractures were experienced during infancy, and the fracture frequency gradually decreased with maturation. Three weeks before her first consultation with our clinic, a fracture in the scapula was experienced. To understand the pathogenesis of bone fragility and establish an effective treatment using medication, BMD and biochemical markers were measured. Informed consent was obtained from the patient in accordance with the Declaration of Helsinki.

Table 1 shows the characteristics of the present patient. The BMD of the lumbar spine (L2-L4) measured by dual energy X-ray absorptiometry (DXA) using a Norland XR-36 instrument (Norland, Fort Atkison, WI, USA) was $0.579 \mathrm{~g} / \mathrm{cm}^{2}$, with a $\mathrm{T}$ score of $55.7 \%$. In particular, the setting of region of interest was carefully performed. The serum calcium and phosphorus levels
Table 1 Characteristics of the Patient

\begin{tabular}{lcl}
\hline \hline Lumbar BMD $\left(\mathrm{g} / \mathrm{cm}^{2}\right)$ & 0.579 & \\
T score of lumbar BMD (\%) & 55.7 & \\
Z score of lumbar BMD (\%) & 55.9 & \\
Face scale score & 7 & $(1-10)$ \\
Serum & & \\
TP (g/dl) & 7.0 & $(6.5-8.2)$ \\
AST (IU/l) & 31 & $(14-32)$ \\
ALT (IU/l) & 26 & $(8-41)$ \\
ALP (IU/l) & 394 & $(135-310)$ \\
BUN (mg/dl) & 11.7 & $(8.0-19.0)$ \\
Creatinine (mg/dl) & 0.4 & $(0.4-0.8)$ \\
Calcium (mg/dl) & 8.8 & $(8.5-10.2)$ \\
Phosphorus (mg/dl) & 3.2 & $(2.8-4.6)$ \\
Intact PTH (pg/ml) & 44 & $(12-61)$ \\
BAP (U/l) & 54.7 & $(9.6-35.4)$ \\
OC (ng/ml) & 9.4 & $(3.1-12.7)$ \\
Undercarboxylated OC (ng/ml) & 28.6 & $(<4.3)$ \\
Urine & & \\
NTX (nmol BCE/mmol Cr) & 96.2 & $(13.0-73.0)$ \\
Calcium/creatinine & 0.43 & $(<0.3)$ \\
\hline
\end{tabular}

Numbers in parentheses are normal ranges. BMD: bone mineral density, TP: total protein, AST: aspartate aminotransferase, ALT: alanin aminotransferase, ALP: alkaline phosphatase, BUN: blood urea nitrogen, PTH: parathyroid hormone, BAP: bone specific alkaline phosphatase, OC: osteocalcin, NTX: cross-linked N-terminal telopeptides of type I collagen.

were within the normal range. The serum bone specific alkaline phosphatase (BAP) and undercarboxylated osteocalcin (OC) levels measured by enzyme immunoassay (EIA), the serum OC level measured by immonoradiometric assay (IRMA), and the urinary cross-linked N-terminal telopeptides of type I collagen (NTX) level measured by enzyme-linked immunosorbent assay (ELISA) were high. The intact parathyroid hormone (PTH) level measured by chemiluminescent immunoassay (CLIA) was within the normal range.

Osteoporosis and bone fragility due to OI were diagnosed 2 weeks after her first consultation. Since then, the patient was treated with alendronate $(5 \mathrm{mg} /$ day) for 18 months. This is a standard alendronate dose in Japan. Table 2 shows the changes in the lumbar (L2L4) BMD, the serum calcium, phosphorus, BAP, OC, and undercarboxylated OC, and urinary NTX levels, and face scale score. In particular, back pain markedly reduced within a couple of months (face scale score decreased from 7 to 2). The lumbar (L2-L4) BMD in the same region of interest as that at baseline increased, and the urinary NTX and serum BAP, OC, and undercarboxylated OC levels, and face scale score decreased, and no new non-vertebral fractures were observed during the 18 months of treatment. The radiographs of the thoracic and lumbar spine obtained after the 18 months of treatment did not show any marked changes in scoliotic deformity and the height of each vertebra, suggesting that no new vertebral fractures had occurred. 
Table 2 Changes in Lumbar BMD, Serum and Urinary Biochemical Markers, and Face Scale Score

\begin{tabular}{lcccc}
\hline \hline & Baseline & Month 6 & Month 12 & Month 18 \\
\hline Lumbar BMD (g/cm²) & 0.579 & 0.656 & 0.678 & 0.684 \\
Serum & & & & \\
$\quad$ Calcium (mg/dl) & 8.8 & 9.0 & 9.7 & 9.8 \\
$\quad$ Phosphorus (mg/dl) & 3.2 & 3.7 & 3.7 & 3.6 \\
BAP (U/l) & 54.7 & 32.4 & 23.6 & 27.0 \\
OC (ng/ml) & 9.4 & 8.8 & 2.9 & 2.8 \\
Undercarboxylated & 28.6 & 27.0 & 7.3 & 4.2 \\
OC (ng/ml) & & & & \\
Urinne & & & & \\
$\quad$ NTX (nmol & 96.2 & 46.6 & 32.6 & 24.3 \\
$\quad$ BCE/mmol Cr) & & & & \\
$\quad$ Calcium/creatinine & 0.43 & 0.32 & 0.26 & 0.24 \\
Face scale score & 7 & 2 & 2 & 2 \\
\hline
\end{tabular}

BMD: bone mineral density, BAP: bone specific alkaline phosphatase, OC: osteocalcin, NTX: cross-linked N-terminal telopeptides of type I collagen.

\section{Discussion}

Osteogenesis imperfecta is a congenital disease of which main characteristic is fragility of bones. Although fragile fractures occur frequently in children with OI, the fracture rate decreases after adolescence due to the influences of sex hormones and maturation. ${ }^{2,13}$ Thus, clinical stability of OI is usually observed with age, and this is an important characteristic of the disease. The present patient had been experiencing fragile fractures frequently during infancy, and the rate of fractures, especially at the long bones, decreased with maturation. However, back pain associated with spinal osteoporosis remained, and she had a fragile fracture in the scapula 3 weeks before her first consultation with our clinic.

The serum undercarboxylated OC level was extremely high in the present patient. The reason for this remains uncertain. It was reported that long-term warfarin treatment impaired carboxylation of osteocalcin, ${ }^{22}$ although the issue of whether long-term warfarin treatment results in decreased the BMD is controversial. $^{23,24} \mathrm{~A}$ higher incidence of femoral neck fractures is observed in patients with higher levels of undercarboxylated OC, ${ }^{25-27}$ suggesting that serum undercarboxylated OC may be associated with the incidence of osteoporotic fractures. Thus, warfarin treatment might play a role in the high level of serum undercarboxylated $\mathrm{OC}$ in the present patient, and the high fracture rate might also be associated with the high level of undercarboxylated OC.

The efficacy of treatment with cyclical intravenous pamidronate for bone fragility in children with OI is established; ${ }^{7-12}$ intravenous pamidronate prevents fragile fractures without inhibiting bone growth. However, oral bisphosphonates may be applicable for adult patients with OI who show high bone turnover as well as for postmenopausal women with osteoporosis, although their efficacy is not yet established.

Osteoporosis in the present patient, a premenopausal woman, was associated with high bone turnover. Available evidence suggests that the classically observed osteopenia in children with OI is associated with increased bone turnover. ${ }^{2-4}$ A histomorphometric study showed that osteoporosis in adult male with OI was associated with increased bone turnover on bone marker measurements, and increased bone resorption and decreased osteoblastic activity at tissue level. ${ }^{28}$ These histomorphometric data support our results.

Treatment with alendronate $(5 \mathrm{mg} /$ day) decreases bone turnover, increases the lumbar BMD (6.21\% for one year), and reduces the incidence of osteoporotic fractures including vertebral fractures in Japanese patients with osteoporosis. ${ }^{16}$ In the present patient, treatment with alendronate $(5 \mathrm{mg} /$ day $)$ decreased bone turnover, improved the lumbar BMD (18.1\% increase for 18 months), reduced back pain, and prevented new vertebral or non-vertebral fractures with a reduction in the serum undercarboxylated OC level. The reduction in the serum undercarboxylated $\mathrm{OC}$ as well as $\mathrm{OC}$ levels might result from the decreased osteoblastic recruitment following suppressed osteoclast-mediated bone resorption, with blood coagulation system unaffected. $^{29}$ The primary endpoint of our treatment was relief of back pain and prevention of new fragile fractures. Treatment with alendronate could achieve our primary endpoint. However, a further period of observation may be needed to determine the long-term efficacy of this treatment for adult patients with OI.

In regard to back pain and treatment with alendronate, Nevitt et al. ${ }^{30}$ have reported that in elderly osteoporotic women those with long-term alendronate treatment showed a significantly lower risk of patients having days of bed rest and limited activity due to back pain. These results suggest that treatment with alendronate in elderly osteoporotic women is efficacious for preventing back pain and subsequent deterioration of activities of daily living. However, the mechanism for reduction of back pain by treatment with alendronate remains uncertain.

The efficacy of bisphosphonates for bone pain in patients with bone resorption-related diseases has been demonstrated. Intravenous pamidronate seems to be a valuable treatment for back pain, as well as rehabilitating elderly patients suffering from chronic and refractory back pain due to osteoporotic vertebral fractures, ${ }^{31}$ and also reduces skeletal pain and biochemical markers of bone resorption in patients with skeletal metastases. ${ }^{32-34}$ Furthermore, risedronate decreases bone pain in patients with Paget's disease of bone. ${ }^{35}$ 
Thus, we believe that suppressed bone resorption might contribute to the relief of back pain in the present patient.

We have already reported the efficacy of treatment with etidronate and alfacalcidol for OI type $\mathrm{I} ;{ }^{36}$ the 18 months of treatment with cyclical oral etidronate and alfacalcidol increased the lumbar BMD by $3.9 \%$, reduced back pain caused by thoracic vertebral fractures (face scale score was reduced from 7 to 2), and prevented new fragile vertebral or non-vertebral fractures in an adult patient with OI type I who had frequently been experiencing fragile fractures in the long bones of the upper and lower extremities. Although the increase in the lumbar BMD seemed to be greater in treatment with alendronate than in that with cyclical etidronate and alfacalcidol, oral bisphosphonates may be efficacious in adult patients with OI type I, who have back pain caused by spinal osteoporosis and have frequently been experiencing fragile fractures.

Side effects of bisphosphonate treatment in children have been reported. First, transient hypocalcemia could be observed during the early period of intravenous pamidronate treatment in children with OI. ${ }^{37}$ Second, acquired osteopetrosis could result from treatment with high dose intravenous pamidronate in a child with unexplained skeletal pain who needed antiresorptive therapy,$^{38}$ suggesting that excessive doses of bisphosponates may compromise skeletal quality in growing patients. However, the safety and tolerability of oral alendronate ( $5 \mathrm{mg}$ daily, physiological dose) have already been established in adult patients with osteoporosis. ${ }^{16,17}$ Thus, we could demonstrate the efficacy of oral alendronate ( $5 \mathrm{mg}$ daily) in our patient with absence of drug-induced toxicities such as sustained hypocalcemia and osteopetrosis.

In conclusion, this report provides evidence indicating that treatment with oral alendronate may have the potential to decrease bone turnover, improve the lumbar BMD, reduce back pain, and prevent new fragile fractures in premenopausal women with OI type I who show high bone turnover.

\section{References}

1. Niyibizi C, Wang S, Mi Z, Robbins PD: Gene therapy approaches for osteogenesis imperfecta. Gene Ther 2004; 11: 408-416

2. Albright JA, Grunt JA: Studies of patients with osteogenesis imperfecta. Bone Joint Surg Am 1971; 53: 1415-1425

3. Baron R, Gertner JM, Lang R, Vignery A: Increased bone turnover with decreased bone formation by osteoblasts in children with osteogenesis imperfecta tarda. Pediatr Res 1983; 17 : 204-207

4. Riley FC, Jowsey J, Brown DM: Osteogenesis imperfecta: morphologic and biochemical studies of connective tissue. Pediatr Res 1973; 7: 757-768
5. Rauch F, Travers R, Parfitt AM, Glorieux FH: Static and dynamic bone histomorphometry in children with osteogenesis imperfecta. Bone 2000; 26: 581-589

6. Brenner RE, Vetter U, Bollen AM, Morike M, Eyre DR: Bone resorption assessed by immunoassay of urinary cross-linked collagen peptides in patients with osteogenesis imperfecta. J Bone Miner Res 1994; 9: 993-997

7. Astrom E, Soderhall S: Beneficial effect of long term intravenous bisphosphonate treatment of osteogenesis imperfecta. Arch Dis Child 2002; 86: 356-364

8. Glorieux FH, Bishop NJ, Plotkin H, Chabot G, Lanoue G, Travers R: Cyclic administration of pamidronate in children with severe osteogenesis imperfecta. N Engl J Med 1998; 339: 947952

9. Glorieux FH: Bisphosphonate therapy for severe osteogenesis imperfecta. J Pediatr Endocrinol Metab 2000; 13: 989-992

10. Gonzalez E, Pavia C, Ros J, Villaronga M, Valls C, Escola J: Efficacy of low dose schedule pamidronate infusion in children with osteogenesis imperfecta. J Pediatr Endocrinol Metab 2001; 14: 529-533

11. Lee YS, Low SL, Lim LA, Loke KY: Cyclic pamidronate infusion improves bone mineralisation and reduces fracture incidence in osteogenesis imperfecta. Eur J Pediatr 2001; 160: 641644

12. Plotkin H, Rauch F, Bishop NJ, Montpetit K, Ruck-Gibis J, Travers R, Glorieux FH: Pamidronate treatment of severe osteogenesis imperfecta in children under 3 years of age. J Clin Endocrinol Metab 2000; 85: 1846-1850

13. King JD, Bobechko WP: Osteogenesis imperfecta. An orthopaedic description and surgical review. J Bone Joint Surg $\mathrm{Br}$ 1971; 53: 72-89

14. Black DM, Cummings SR, Karpf DB, Cauley JA, Thompson DE, Nevitt MC, Bauer DC, Genant HK, Haskell WL, Marcus R, et al: Randomised trial of effect of alendronate on risk of fracture in women with existing vertebral fractures. Fracture Intervention Trial Research Group. Lancet 1996; 348: 1535-1541

15. Cummings SR, Black DM, Thompson DE, Applegate WB, Barrett-Connor E, Musliner TA, Palermo L, Prineas R, Rubin SM, Scott JC, et al: Effect of alendronate on risk of fracture in women with low bone density but without vertebral fractures: results from the Fracture Intervention Trial. JAMA 1998; 280: 20772082

16. Shiraki M, Kushida K, Fukunaga M, Kishimoto H, Taga M, Nakamura T, Kaneda K, Minaguchi H, Inoue T, Morii H, et al: A double-masked multicenter comparative study between alendronate and alfacalcidol in Japanese patients with osteoporosis. The Alendronate Phase III Osteoporosis Treatment Research Group. Osteoporos Int 1999; 10: 183-192

17. Tonino RP, Meunier PJ, Emkey R, Rodriguez-Portales JA, Menkes CJ, Wasnich RD, Bone HG, Santora AC, Wu M, Desai $\mathrm{R}$, et al: Skeletal benefits of alendronate: 7-year treatment of postmenopausal osteoporotic women. Phase III Osteoporosis Treatment Study Group. J Clin Endocrinol Metab 2000; 85: 3109-3115

18. Fleisch H, Reszka A, Rodan G, Rogers M. Bisphosphonates: Mechanism of action. In: Bilezikian JP, Raisz LG, Rodan GA, eds, Principles of Bone Biology. 2nd Ed, CA, Academic Press 2002; 1361-1385

19. Sillence DO: Osteogenesis imperfecta nosology and genetics. Ann NY Acad Sci 1988; 543: 1-15

20. Orimo H, Sugioka Y, Fukunaga M, Muto Y, Hotokebuchi T, Gorai I, Nakamura T, Kushida K, Tanaka H, Ikai T, Oh-hashi Y: Diagnostic criteria of primary osteoporosis. J Bone Miner Metab 1998; 16: 139-150

21. Orimo H, Hayashi Y, Fukunaga M, Sone T, Fujiwara S, Shiraki M, Kushida K, Miyamoto S, Soen S, Nishimura J, et al: Osteo- 
porosis Diagnostic Criteria Review Committee: Japanese Society for Bone and Mineral Research: Diagnostic criteria for primary osteoporosis: year 2000 revision. J Bone Miner Metab 2001; 19: 331-317

22. Menon RK, Gill DS, Thomas M, Kernoff PB, Dandona P: Impaired carboxylation of osteocalcin in warfarin-treated patients. J Clin Endocrinol Metab 1987; 64: 59-61

23. Jamal SA, Browner WS, Bauer DC, Cummings SR: Warfarin use and risk for osteoporosis in elderly women. Study of Osteoporotic Fractures Research Group. Ann Intern Med 1998; 28: 829832

24. Philip WJ, Martin JC, Richardson JM, Reid DM, Webster J, Douglas AS: Decreased axial and peripheral bone density in patients taking long-term warfarin. QJM 1995; 88: 635-640

25. Plantalech L, Guillaumont M, Vergnaud P, Leclercq M, Delmas PD: Impairment of gamma carboxylation of circulating osteocalcin (bone gla protein) in elderly women. J Bone Miner Res 1991; 6: 1211-1216

26. Szulc P, Chapuy MC, Meunier PJ, Delmas PD: Serum undercarboxylated osteocalcin is a marker of the risk of hip fracture in elderly women. J Clin Invest 1993; 91: 1769-1774

27. Vergnaud P, Garnero P, Meunier PJ, Breart G, Kamihagi K, Delmas PD: Undercarboxylated osteocalcin measured with a specific immunoassay predicts hip fracture in elderly women: the EPIDOS Study. J Clin Endocrinol Metab 1997 Mar; 82: 719-724

28. Iwamoto J, Takeda T, Ichimura S: Increased bone resorption with decreased activity and increased recruitment of osteoblasts in osteogenesis imperfecta type I. J Bone Miner Metab 2002; 20: 174-179

29. Nagata I, Aoki Y, Tsuchimoto M, Horiuchi H, Kishimoto T, Kiyoki M: General Pharmacological effects of alendronate (AHBuBP): effects of urinary excretion, blood system and immune system. Pharmacometrics 1995; 49: 541-548 (in Japanese)

30. Nevitt MC, Thompson DE, Black DM, Rubin SR, Ensrud K, Yates AJ, Cummings SR: Effect of alendronate on limited- activity days and bed-disability days caused by back pain in postmenopausal women with existing vertebral fractures. Fracture Intervention Trial Research Group. Arch Intern Med 2000; 160: $77-85$

31. Gangji V, Appelboom T: Analgesic effect of intravenous pamidronate on chronic back pain due to osteoporotic vertebral fractures. Clin Rheumatol 1999; 18: 266-267

32. Glover D, Lipton A, Keller A, Miller AA, Browning S, Fram RJ, George S, Zelenakas K, Macerata RS, Seaman JJ: Intravenous pamidronate disodium treatment of bone metastases in patients with breast cancer. A dose-seeking study. Cancer 1994; 74: 29492955

33. Hortobagyi GN, Theriault RL, Porter L, Blayney D, Lipton A, Sinoff C, Wheeler H, Simeone JF, Seaman J, Knight RD: Efficacy of pamidronate in reducing skeletal complications in patients with breast cancer and lytic bone metastases. Protocol 19 Aredia Breast Cancer Study Group. N Engl J Med 1996; 335: 1785-1791

34. Iwamoto J, Takeda T, Ichimura S: Transient relief of metastatic cancer bone pain by oral administration of etidronate. $\mathrm{J}$ Bone Miner Metab 2002; 20: 228-234

35. Siris ES, Chines AA, Altman RD, Brown JP, Johnston CC Jr, Lang R, McClung MR, Mallette LE, Miller PD, Ryan WG, et al: Risedronate in the treatment of Paget's disease of bone: an open label, multicenter study. J Bone Miner Res 1998; 13: 1032-1038

36. Iwamoto J, Matsu K, Takeda T, Ichimura S, Uzawa M: Effects of treatment with etidronate and alfacalcidol for osteogenesis imperfecta type I: a case report. J Orthop Sci 2003; 8: 243-247

37. Rauch F, Plotkin H, Travers R, Zeitlin L, Glorieux FH: Osteogenesis imperfecta types I, III, and IV: effect of pamidronate therapy on bone and mineral metabolism. J Clin Endocrinol Metab 2003; 88: 986-992

38. Whyte MP, Wenkert D, Clements KL, McAlister WH, Mumm S: Bisphosphonate-induced osteopetrosis. N Engl J Med 2003; 349: 457-463 